03

\title{
Структура течения и изменение тяги при вдуве струи газа в сверхзвуковую часть сопла
}

\author{
(C) К.Н. Волков, В.Н. Емельянов, М.С. Яковчук \\ Балтийский государственный технический университет, \\ 190005 Санкт-Петербург, Россия \\ e-mail: dsci@mail.ru
}

(Поступило в Редакцию 31 января 2018 г. В окончательной редакции 4 октября 2018 г.)

Рассмотрены численное моделирование газодинамических процессов, сопровождающих поперечный вдув струи газа в сверхзвуковую часть сопла, применительно к созданию управляющих усилий в ракетных двигателях. Численные расчеты проведены на основе различных моделей турбулентности при изменении массового расхода вдуваемого газа. Результаты расчетов, полученные в рамках невязкой, ламинарной и турбулентной постановки задачи, сравнены между собой и с данными физического эксперимента. Обсуждено формирование ударно-волновой и вихревой картины течения. Сделаны выводы о влиянии входных параметров задачи на коэффициент усиления тяги.

DOI: 10.21883/JTF.2019.03.47168.47-18

\section{Введение}

Для управления вектором тяги ракетных двигателей используется несимметричный вдув газа в сверхзвуковую часть сопла $[1,2]$. Такой способ управления вектором тяги характеризуется сравнительной простотой изготовления соответствующих устройств, высокими динамическими параметрами, исключением подвижных элементов, реагирующих с основным потоком, отсутствием потерь осевой тяги.

Проектирование органов управления вектором тяги связано с определением нагрузок, действующих на сопло. Задача определения газодинамических сил, действующих на элементы конструкции неподвижного сопла при симметричном истечении продуктов сгорания, не представляет трудностей и решается при помощи расчета распределения давления по длине сопла с последующим интегрированием сил давления в основном направлении [3].

Возмущенная пристеночная зона, возникающая при вдуве газа в закритическую часть сопла, разделяется на две части: вверх и вниз по течению от отверстия вдува. Коэффициент усиления тяги для первой части области, характеризуемой отрывом потока перед струйным препятствием, равняется 1.5-1.8 [4], а коэффициент усиления для второй области увеличивается пропорционально $\left(l / d_{e}\right)^{1 / 2}$, где $l-$ расстояние отверстия вдува от выходного сечения сопла, $d_{e}$ - эквивалентный диаметр отверстия, зависящий от отношения расходов вторичного и основного потоков.

Для сопел с расчетным режимом течения или с малым перерасширением условия на срезе сопла не оказывают существенного влияния на картину взаимодействия при вдуве струи в основной сверхзвуковой поток. При наличии определенной степени перерасширения потока в сопле картина взаимодействия становится более сложной $[2,5]$.
Данные физического эксперимента по взаимодействию струи со сверхзвуковым потоком приводятся в работах [6-8] (холодный газ) и $[9,10]$ (стендовые испытания). Корреляционные зависимости, позволяющие рассчитать тяговые характеристики сопла в зависимости от параметров вдуваемого газа, приводятся в работах $[11,12]$, а зависимости для расчета глубины проникновения струи в сверхзвуковой поток и размера диска Маха — в работах $[13,14]$.

Математическая модель и методика расчета инжекционных органов управления обсуждаются в работе [15]. Модели для оценки величины и координаты точки приложения боковой силы, возникающей при вдуве недорасширенной струи газа в сопло, рассматриваются в работе [1]. Упрощенные модели учитывают, как правило, отрыв пограничного слоя перед инжектируемой струей и перераспределение давления за головным скачком уплотнения. Для определения управляющей силы находится площадь проекции поверхности скачка уплотнения на поверхность сопла (эта площадь ограничена линией пересечения конического скачка со стенками сопла).

Расчетные исследования проводятся в работе [16] на основе интегрирования трехмерных уравнений Эйлера, а также на основе решения осредненных по Рейнольдсу уравнений Навье-Стокса, замкнутых при помощи алгебраической модели турбулентности [17] и модели $k-\varepsilon$ [18]. Сравнение точности и возможностей различных моделей турбулентности обсуждается в работе [19]. Результаты расчетов, проведенных в работе [20], показывают, что при малых отношениях давления в струе и давления в основном потоке наиболее точные результаты по распределению давления на стенке дает RNG $k-\varepsilon$-модель турбулентности, а при высоких перепадах давления - модель SST. При этом модель Спаларта-Аллмареса дает наименее точные результаты среди всех моделей турбулентности. Вдув струи с 


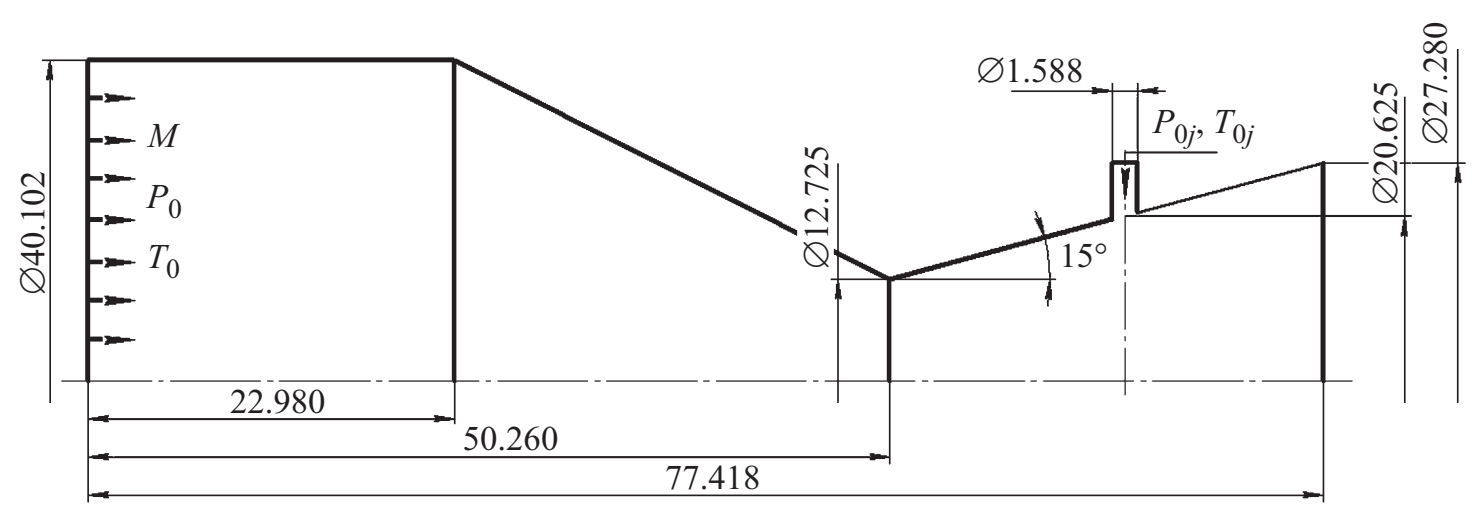

Рис. 1. Геометрия сопла.

поверхности плоской пластины в сверхзвуковой поток исследуется в работе [21-25].

Численное моделирование вдува струи газа в сверхзвуковую часть сопла на основе стандартной $k-\varepsilon$-модели турбулентности проводится в работе [26]. Отверстие вдува располагается примерно посередине сверхзвукового участка сопла под углом $15^{\circ}$ к оси сопла (угол отсчитывается по часовой стрелке от оси сопла). В расчетах варьируется массовый расход вдуваемого газа, который изменяется от 1 до $10 \%$ от массового расхода газа через сопло. Результаты расчетов по коэффициенту усиления находятся в хорошем согласовании с данными физического эксперимента [9] и расчетами [16].

В случае вдува струи с поверхности плоской пластины детальное сравнение с данными физического эксперимента, приведенными в работе [7], производилось для различных перепадов давления [23, 24]. В работе [21] проведено численное моделирование задачи с помощью модели SST и получено согласие результатов расчета с экспериментальной работой [7]. В работе [22] отмечается, что SST-модель турбулентности дает точные результаты лишь при высоких перепадах давления. При низких перепадах давления наилучшим выбором является Realizable $k-\varepsilon$-модель. Результаты численных расчетов также сравниваются с экспериментальными данными [7]. Вопрос о выборе модели турбулентности остается открытым. В связи с этим в настоящей работе проводится исследование точности различных моделей турбулентности применительно к вдуву струи в сопло. Детальные экспериментальные данные по вдуву струи в расширяющуюся часть сопла, по-видимому, отсутствуют, что связано как с трудностью постановки физического эксперимента, так и большим разнообразием форм каналов твердого топлива, используемых на практике.

Моделирование крупных вихрей взаимодействия сверхзвукового потока в канале со струей, вдуваемой по нормали к стенке канала, проводится в работах [27-29]. Для расчетов используются подробные сетки, мелкие шаги по времени и разностные схемы высокого порядка точности.
В настоящей работе рассматривается взаимодействие поперечной струи вдуваемого газа со сверхзвуковым потоком в сопле. Расчеты проводятся на основе различных моделей турбулентности при варьировании массового расхода вдуваемого газа. Полученные распределения характеристик потока используются для нахождения тяги сопла при наличии вдува струи в сверхзвуковой поток. Результаты расчетов по коэффициенту усиления тяги сопла сравниваются с расчетами на основе модели невязкого сжимаемого газа и с данными физического эксперимента. Работа является одним их этапов по проверке точности и работоспособности различных моделей турбулентности, давая возможность перейти к более сложной постановке задачи, связанной со вдувом импульсной струи в сверхзвуковой поток в сопле, а также к задаче, связанной с выбором оптимальных параметров вдуваемой струи.

\section{Геометрическая модель}

Геометрия сопла, используемая в расчетах, соответствует работе [6], в которой приводятся данные физического эксперимента, и представлено на рис. 1 (длины приводятся в миллиметрах). Задача является симметричной относительно плоскости, проходящей через отверстие вдува, поэтому расчетная область содержит половину проточной части соплового тракта. Вдув струи в закритическую часть сопла производится по нормали к оси сопла через круглое отверстие диаметром $d_{j}=1.588 \mathrm{~mm}$. Конфузорный и диффузорный участки сопла имеют коническую форму с углами наклона образующей конуса с оси сопла $12.725^{\circ}$ и $15^{\circ}$.

Поскольку наибольший интерес представляет сверхзвуковая область течения, в которой реализуется поперечный вдув струи, то области, соответствующие дозвуковой части сопла и предшествующему участку газодинамического тракта (рис. 2,a), исключаются из рассмотрения (возмущения не передаются вверх по потоку). Расчеты проводятся в части области, приведенной на рис. 2, $b$. Цифры $1-4$ соответствуют границам и поверхностям, на которых задаются граничные условия. 


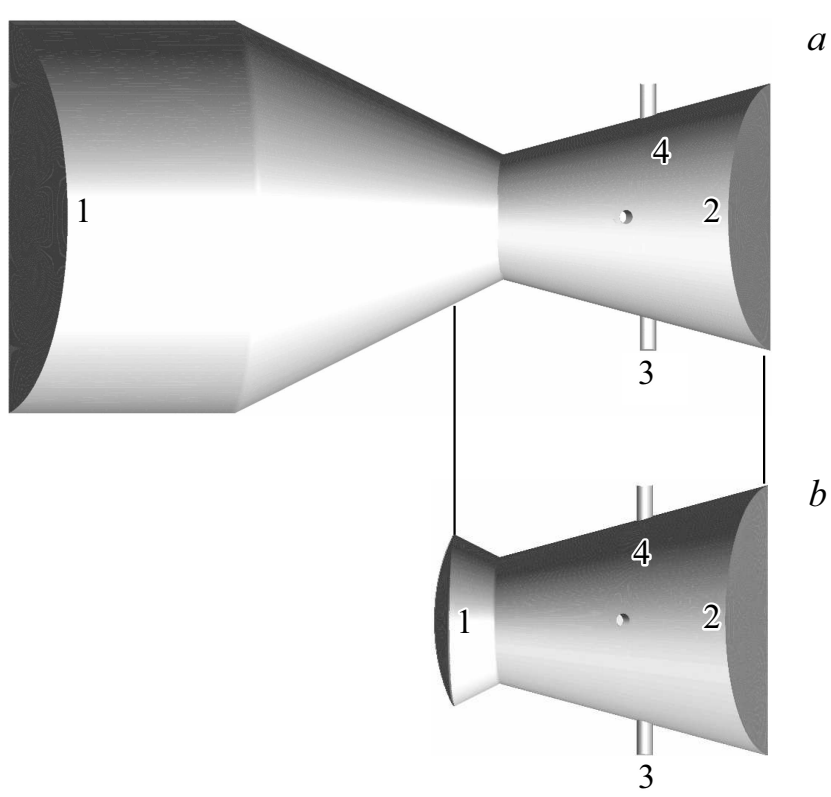

Рис. 2. Конфигурация полной расчетной области $(a)$ и ее части $(b)$.

\section{Граничные условия}

Для сокращения времени, необходимого для решения нестационарной задачи, используется передача данных с одной модели на другую (метод декомпозиции). Для постановки граничных условий во входном сечении расчетной области используется ее декомпозиция на два блока, соответствующих каналу заряда и сопловому блоку. Начальное поле течения (течение при отсутствии вдува) рассчитывается во всей области. Выбирается сечение модели, в котором влияние возмущений, создаваемых вдувом струи, является незначительным, и определяются параметры потока в этом сечении. Сравнение распределений параметров потока, полученных на основе полного и упрощенного подходов, показывает, что метод декомпозиции приводит к погрешности, не превышающей 1\% при заданной интенсивности вдува.

Для корректной постановки граничных условий во входном сечении проводится расчет течения во всей расчетной области, включая канал заряда и сопловой блок (в расчетах $\operatorname{Re}=1.87 \cdot 10^{7}$ ). При моделировании вдува струи входное сечение расчетной области располагается на достаточном удалении от отверстия вдува.

Во входном сечении расчетной области (граница 1 рис. 2) задается массовый расход ( $\dot{m}=1.32 \mathrm{~kg} / \mathrm{s})$, полная температура $\left(T_{0}=1200 \mathrm{~K}\right)$, а также радиальные профили скорости и характеристик турбулентности, полученные из осесимметричного расчета течения продуктов горения в канале заряда.

В выходном сечении сопла (граница 2) задается статическое давление. В случае сверхзвукового течения давление в выходном сечении сопла определяется при помощи экстраполяции решения из внутренних узлов, а в случае дозвукового течения используется атмосферное давление.

Во входном сечении сопла вдува (граница 3) задаются полное давление $p_{0 j}$ (этот параметр варьируется), полная температура $T_{0 j}=298 \mathrm{~K}$ и характеристики турбулентности (степень турбулентности составляет $0.1 \%$, а гидравлический диаметр - $1.6 \mathrm{~mm}$ ).

Для скорости на поверхности сопла (граница 4) используются граничные условия непротекания и прилипания для нормальной и тангенциальной скорости. Стенки сопла считаются теплоизолированными. Характеристики турбулентности на стенке находятся при помощи метода пристеночных функций.

\section{Расчетная сетка}

Для построения блочно-структурированной сетки применяется разбиение физического объема на ряд непересекающихся блоков, в каждом из которых разрешение сетки подбирается исходя из газодинамических особенностей течения.

Сетки для полной расчетной области (при отсутствии вдува) и для части расчетной области (при вдуве струи заданной интенсивности) представлены рис. 3. Расчеты течения в сопле с поперечным вдувом струи проводятся на сетке, содержащей около одного миллиона ячеек.
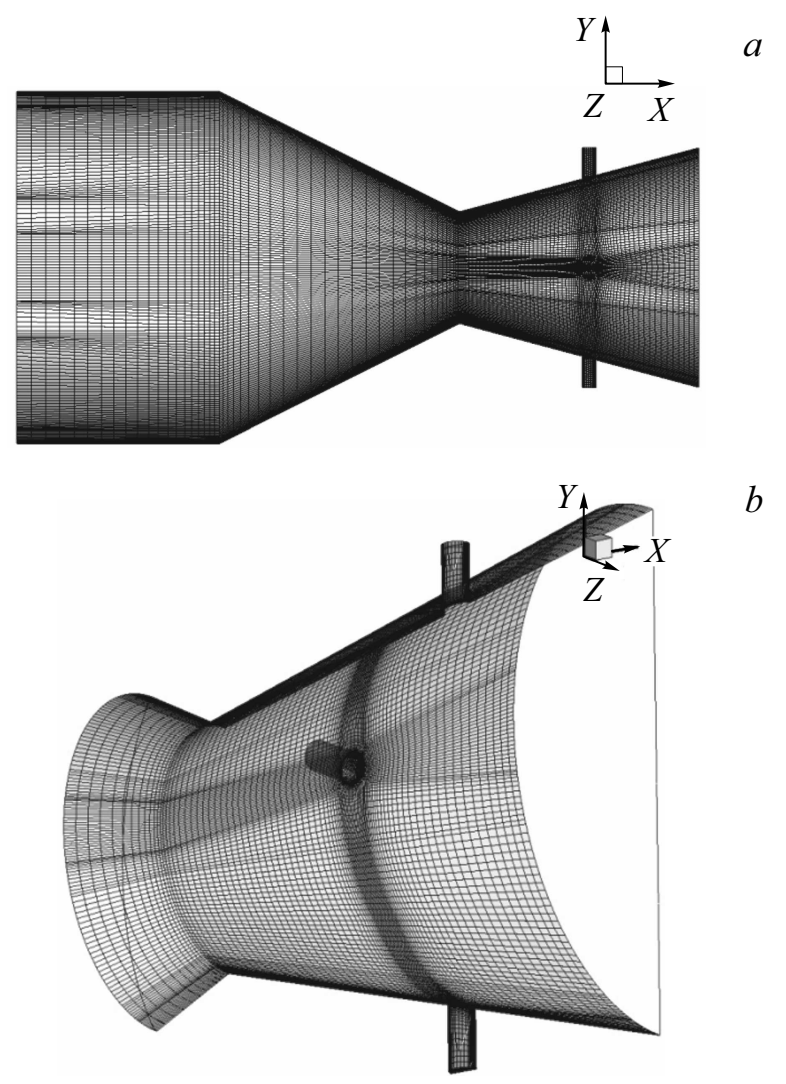

$b$

Рис. 3. Расчетная сетка в полной расчетной области $(a)$ и в ее части, используемой в расчетах $(b)$. 


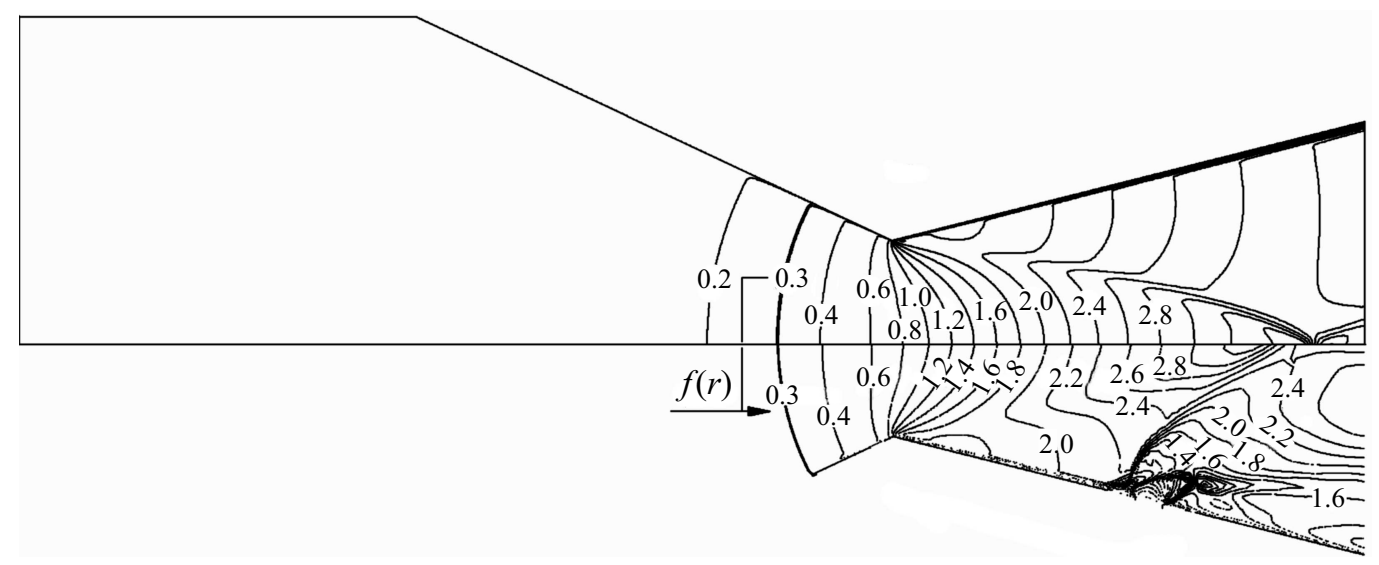

Рис. 4. Линии уровня числа Маха, полученные для полной расчетной области (сверху) и для ее части (снизу).

Производится сгущение координатных линий сетки около критического сечения сопла и около отверстия вдува. Узлы сетки сгущаются также около стенок сопла для надлежащего разрешения пограничного слоя.

Безразмерная пристеночная координата $y^{+}$принимает максимальные значения в окрестности критического сечения сопла, где $y^{+}=56$, а также в области, соответствующей вдуваемой струе, в которой $y^{+}=42$. В дозвуковой и сверхзвуковой частях сопла координата $y^{+}$имеет практически равномерное распределение, причем $y^{+}=15$ в суживающейся части сопла и $y^{+}=24$ в расширяющейся части сопла.

\section{Вычислительная процедура}

Расчеты проводятся на основе осредненных по Рейнольдсу уравнений Навье-Стокса, замкнутых при помощи различных моделей турбулентности. В расчетах используются модель Спаларта-Аллмареса, Realizable $k-\varepsilon$-модель имодель SST. В качестве рабочей среды используется воздух. Теплофизические свойства - справочные с учетом их зависимости от температуры.

Дискретизация основных уравнений осуществляется при помощи метода конечных объемов и метода поправки давления SIMPLE. Для дискретизации конвективных и диффузионных потоков используются противопоточные и центрированные разностные схемы 2-го порядка точности с расщеплением вектора потока по методу Poe, а для дискретизации по времени - неявная схема 2-го порядка точности. Система разностных уравнений решается методом LU-SGS. Число Куранта изменяется от 2 до 7.

Для контроля сходимости итерационного процесса проверяется уровень невязки искомых функций и выполнение интегрального уравнения неразрывности. Расчеты прекращаются, когда уровень невязки всех искомых функций уменьшается на три порядка, а рассогласование массовых расходов на входных и выходных границах расчетной области становится меньше, чем $10^{-3} \mathrm{~kg} / \mathrm{s}$.

\section{Результаты расчетов}

В расчетах варьируется интенсивность вдуваемой струи, соответствующая как звуковому, так и дозвуковому вдуву. Сравнение расчетных и экспериментальных данных проводится по величине управляющего усилия в зависимости от интенсивности вдува.

Результаты расчетов, полученные как для полной области (расчет в осесимметричной постановке), так и для ее части (расчет в трехмерной постановке) и приведенные на рис. 4 , достаточно хорошо согласуются между собой, что подтверждает возможность декомпозиции расчетной области. Рассогласование чисел Маха, рассчитанных в рамках полного и упрощенного подходов (рис. 2), не превышает $1 \%$.

Инжектируемое рабочее тело является для основного потока препятствием, приводящим к перераспределению давления на внутренней поверхности сопла. Сверхзвуковой поток, набегая на инжектируемую струю, отрывается от стенки сопла. Перед отверстием образуется незамкнутая застойная зона с двумя вихрями, вращающимися в противоположных направлениях. За отверстием также возникает застойная зона с одним вихрем. Непосредственно перед вдуваемой струей формируется слабая ударная волна, а перед верхней частью границы струи возникает криволинейный скачок уплотнения. За ударной волной образуется система волн разрежения, а в окрестности присоединения вторичного потока к стенке сопла возникает хвостовой скачок уплотнения [23].

Формирование трехмерных вихревых структур поясняет рис. 5. Вниз по течению от головного скачка уплотнения формируется пара вихрей, вращающихся в противоположные стороны. Отрыв пограничного слоя и формирование рециркуляционной зоны перед отверстием вдува приводят к образованию подковообразного вихря, который огибает инжектируемую струи с обеих сторон [25]. Интенсивность возникающих ударноволновых структур и вихревых образований определяется отношением давлений во вдуваемой струе и в основном потоке, числом Маха основного потока, формой отвер- 

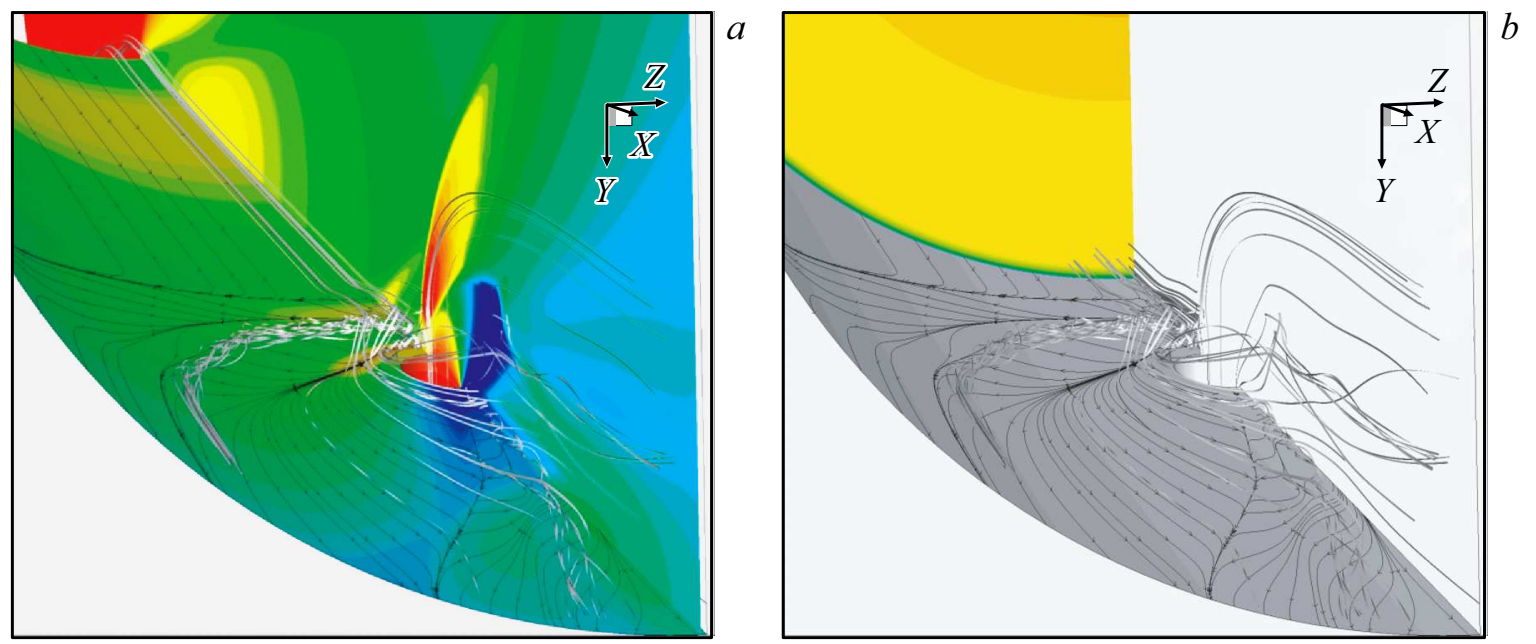

Рис. 5. Линии уровня давления на стенке сопла и плоскости симметрии (a) и линии растекания газа по поверхности сопла $(b)$.

стия вдува и местоположением вдуваемой струи, а также рядом других параметров [30].

Сравнение распределений давления на стенке сопла в плоскости симметрии показывает рис. 6. Линия 1 соответствует модели Спаларта-Аллмареса, линия 2 модели Realizable $k-\varepsilon$, линия 3 - модели SST, а линия 4 - модели невязкого газа. При этом имеется существенное различие в распределениях давления, рассчитанных при помощи модели невязкого газа (линия 4) и моделей турбулентного течения (линии $1-3$ ). В то время как модели турбулентного течения, используемые в расчетах, дают схожие распределения давления в области, расположенной вниз по течению от отверстия вдува, распределения давления перед вдуваемой струей в существенной степени различаются.

При инжекции газа в область сверхзвукового потока происходит отрыв турбулентного пограничного слоя с последующим возникновением конического скачка уплотнения переменной интенсивности. В результате за скачком уплотнения образуется область повышенного давления (по сравнению с противоположным участком сопла, где вдув газа отсутствует), что обусловливает возникновение управляющего усилия. При известных параметрах основного потока можно определить угол наклона скачка, угол отрыва, параметры за скачком и в области отрыва.

Расчет характеристик инжекционных органов управления сводится к определению величины управляющей силы, возникающей при инжекции газа и к расчету расхода вдуваемого газа, необходимого для обеспечения заданного уровня управляющей силы. Результирующая управляющая сила является суммой силы, обусловленной увеличением давления в зоне отрыва, силы, обусловленной увеличением давления на стенках сопла в области между зоной отрыва и скачком уплотнения, а также силы, которая определяется количеством движения инжектируемого рабочего тела.

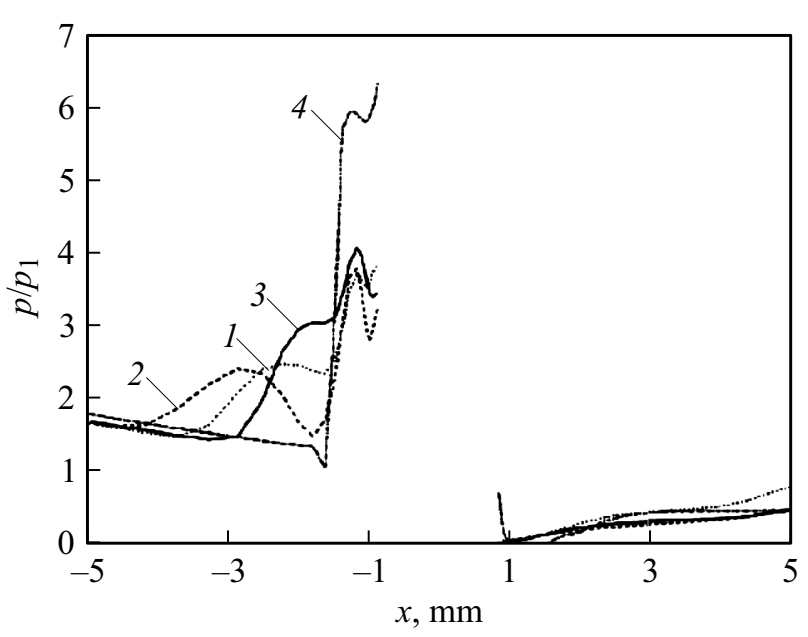

Рис. 6. Распределения давления на стенке сопла в плоскости симметрии.

В области отрыва (перед отверстием) имеет место резкое повышение давления, а за отверстием - понижение давления. Боковое усилие при инжектировании вторичного рабочего тела образуется в результате реакции вдуваемой струи и неуравновешенного избыточного поля давления в зоне возмущения.

Управляющее усилие представляет собой сумму тяги сопла вдува и силы, приложенной к стенкам основного сопла. Тяга сопла вдува вычисляется при помощи соотношения

$$
P_{1}=\int_{F_{j}}\left(\rho v_{y}^{2}+p\right) d F=\sum_{N_{1}}\left(\rho v_{y}^{2}+p\right)_{w} n_{y w} F_{w},
$$

где $N_{1}$ - число граней контрольных объемов вдоль контура интегрирования (сопло вдува). Сила, приложенная к стенкам основного сопла и возникающая вследствие перераспределения давления в области взаимодействия 


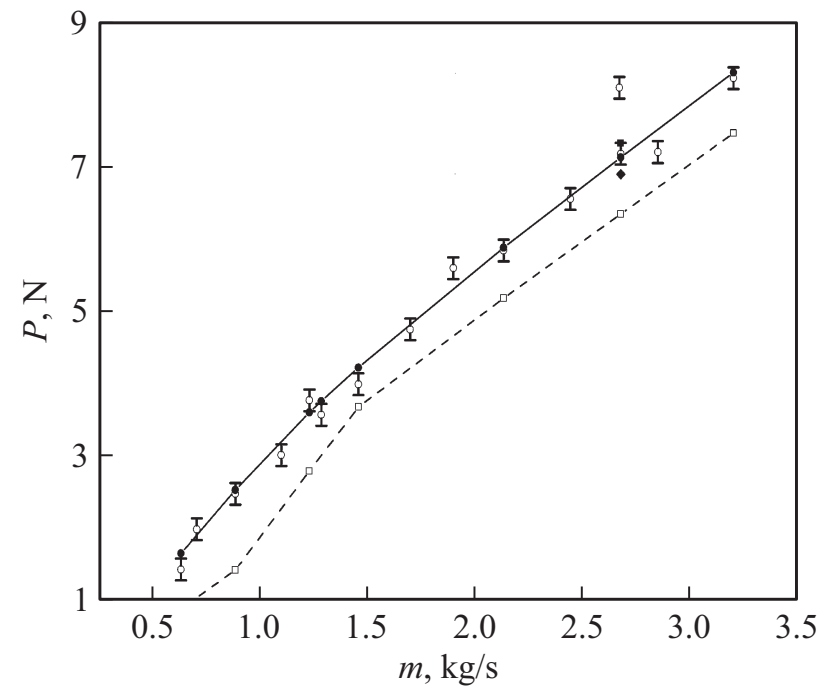

Рис. 7. Влияние массового расхода вдуваемого газа на управляющее усилие.

потоков, вычисляется при помощи интегрирования статического давления по внутренней поверхности стенок сопла

$$
P_{2}=\int_{F_{w}} p n_{y} d F=\sum_{N_{2}} p_{w} n_{y w} F_{w},
$$

где $N_{2}$ - число граней контрольных объемов вдоль контура интегрирования (основное сопло). В приведенных соотношениях под $\rho, p$ и $v_{y}$ понимаются плотность, давление и нормальная компоненты скорости. Площадь и проекция нормали на ось $y$ обозначаются через $F$ и $n_{y}$. Индексы $j$ и $w$ относятся к поверхности сопла вдува и поверхности основного сопла.

Расход вдуваемого газа (интенсивность вдува) оказывает существенное влияние на величину реактивной составляющей управляющего усилия, а также на глубину проникновения струи в поток и размеры возмущенной зоны. Влияние массового расхода вдуваемого газа на управляющее усилие показывает рис. 7. Сплошная линия соответствует результатам расчетов на основе модели SST, светлые значки - результатам расчетов на основе модели Спаларта-Аллмареса, а темные значки - результатам расчетов на основе модели Realizable $k-\varepsilon$ (они практически сливаются с другими значками). Результаты расчетов, показанные штриховой линией, получены на основе модели невязкого сжи- маемого газа. Пустой кружок соответствуют данным физического эксперимента [6].

Результаты численного моделирования на основе различных моделей турбулентности находятся в хорошем согласовании друг с другом и с данными физического эксперимента [6]. Расчетные данные при изменении массового расхода вдуваемого газа находятся в качественном согласовании с результатами физического эксперимента [26] и численного моделирования [16], полученными для иной геометрии сопла.
Рассогласование результатов расчетов при помощи различных моделей турбулентности составляет несколько процентов. В то же время имеется существенное влияние вязких эффектов на интенсивность силового взаимодействия потока со стенками. Моделирование с подключением модели турбулентности SST наиболее точно воспроизводит экспериментальные данные [6]. Другие модели турбулентности (модель Спаларта-Аллмараса и модель Realizable $k-\varepsilon$ ) показывают незначительное рассогласование. Расчеты по модели невязкого течения дают лишь качественное согласование с данными физического эксперимента [6]. Максимальное различие результатов расчетов, полученных в рамках модели турбулентного течения и модели невязкого сжимаемого газа, достигает $12 \%$.

\section{Заключение}

Проведено численное моделирование пространственного взаимодействия поперечной струи вдуваемого газа со сверхзвуковым потоком в сопле (вдув осуществляется в сверхзвуковой части сопла). В расчетах варьируется интенсивность вдуваемой струи, соответствующая как до-, так и звуковому вдуву, и исследуется влияние массового расхода вдуваемого газа на величину управляющего усилия.

Результаты расчетов в рамках различных моделей турбулентности находятся в достаточно хорошем согласовании друг с другом и с данными физического эксперимента. Сравнение результатов расчетов, проведенных на основе модели невязкого сжимаемого газа и модели турбулентного течения, показывает существенное влияние вязких эффектов на интенсивность силового взаимодействия инжектируемого потока со стенками сопла. Рассогласование результатов расчетов, полученных в рамках модели турбулентного течения и модели невязкого сжимаемого газа, достигает $12 \%$.

\section{Список литературы}

[1] Органы управления вектором тяги твердотопливных ракет / Под ред. Н.П. Кузнецова. Москва-Ижевск: НИЦ „Регулярная и хаотическая динамика“, 2006. 552 с.

[2] Краснов Н.Ф., Кошевой В.Н., Калугин В.Т. Аэродинамика отрывных течений. М.: Высшая школа, 1988. 351 с.

[3] Пирумов У.Г., Росляков Г.С. Газовая динамика сопел. М.: Наука, 1990. 368 с.

[4] Шишков А.А., Панин С.Д., Румянщев Б.В. Рабочие процессы в РДТТ. М.: Машиностроение, 240 с.

[5] Hassan E., Boles J., Hikaru A., Davis D., Shyy W. // Progress in Aerospace Sciences. 2013. Vol. 57. P. 1-24.

[6] Walker R.E., Stone A.R., Shandor M. // AIAA Journal. 1963. Vol. 1. N 2. P. 334-338.

[7] Spaid F.W., Zucoski E.E. // AIAA Journal. 1968. Vol. 6. N 2. P. 205-211.

[8] Masuya G. // AIAA Journal. 1977. Vol. 15. N 3. P. 301-302. 
[9] Inouye T. Experiments on rocket thrust vector control by hot gas injection // J. Spacec. Rockets. 1966. Vol. 3. N 4. P. 737-739.

[10] Zeierman I., Timnat Y.M. // J. Spacec. Rockets. 1973. Vol. 10. N 3. P. $161-162$.

[11] Broadwell J.E. // AIAA Journal. 1963. Vol. 1. N 5. P. 1067-1075.

[12] Walker R.E., Shandor M. // J. Spacec. Rockets. 1964. Vol. 1. N 4. P. 409-413.

[13] Gruber M., Nejad A.S., Chen T.H., Dutton J.C. // J. Propulsion and Power. 2000. Vol. 16. N 3. P. 449-457.

[14] Portz R., Segal C. // AIAA Journal. 2006. Vol. 44. N 10. P. 2426-2429.

[15] Калугин B.T. Аэрогазодинамика органов управления полетом летательных аппаратов. М.: Изд-во МГТУ, 2004. 688 с.

[16] Balu R., Marathe A.G., Paul P.J., Mukunda H.S. // J. Propulsion and Power. 1991. Vol. 7. N 4. P. 580-585.

[17] Dhinagram R., Bose T.K. // AIAA Paper. 1996. N 96-0453.

[18] Ko H., Yoon W. // J. Propulsion and Power. 2002. Vol. 18. N 3. P. 585-591.

[19] Erdem E., Albayrak K., Tinaztepe H.T. // AIAA Paper. 2006. N 2006-4942.

[20] Huang W., Liu W.D., Li S.B., Xia Z.X., Liu J., Wang Z.G. // Acta Astronautica. 2012. Vol. 73. P. 1-9.

[21] Федорова Н.Н., Федорченко И.А., Федоров А.В. // Прикладная механика и техническая физика. 2013. Т. 54. № 2. C. 51-74.

[22] Huang W., Wang Z.-G., Wu J.-P., Li S.-B. // Aerospace Science and Technology. 2013. Vol. 28. N 1. P. 91-99.

[23] Волков К.Н., Емельянов В.Н., Яковчук М.С. // Прикладная механика и техническая физика. 2015. Т. 56. № 5. C. $64-75$.

[24] Волков К.Н., Емельянов В.Н., Яковчук М.С. // Инженернофизический журнал. 2017. Т. 90. № 6. С. 1512-1517.

[25] Волков К.Н., Емельянов В.Н., Яковчук М.С. // Прикладная механика и техническая физика. 2017. Т. 58. № 6. C. $114-125$.

[26] Prince R.L., Rejith P., Balu R. // Procedia Engineering. 2012. Vol. 38. P. 1745-1749.

[27] Lavante E., Zeitz D., Kallenberg M. // Journal of Propulsion and Power. 2001. Vol. 17. N 6. P. 1319-1326.

[28] Peterson D.M., Subbareddy P.K., Candler G.V. // AIAA Paper. 2006. N 2006-8128.

[29] Kawai S., Lele S.K. // AIAA Paper. 2008. N 2008-4575.

[30] Gruber M.R., Nejad A.S., Chen T.H., Dutton J.C // Experiments in Fluids. 1997. Vol. 22. N 5. P. 397-407. 